\title{
Cuantificación sistematizada de la remodelación vascular in vitro en la morbilidad gestacional asociada al síndrome antifosfolípido
}

\author{
Manuela Velásquez B. ${ }^{1, a}$, Ángela M. Álvarez G. ${ }^{1, b}$, Ángela P. Cadavid J. ${ }^{1, C}$ \\ ${ }^{1}$ Grupo Reproducción, Facultad de Medicina, Universidad de Antioquia. Colombia.
}

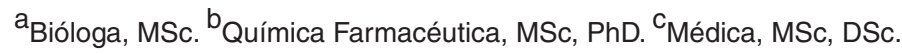

\section{RESUMEN}

Antecedentes: El síndrome antifosfolípido (SAF) se caracteriza por manifestaciones clínicas de trombosis o morbilidad gestacional y la presencia de anticuerpos antifosfolípidos (aAFL), que se pueden unir al trofoblasto o al endotelio materno, alterando la placentación normal. Objetivo: Evaluar el efecto del suero de mujeres con SAF en un modelo tridimensional de remodelación vascular in vitro. Métodos: Cuantificación sistematizada con el programa Image $\mathrm{J}$ y el complemento Angiogenesis Analyzer de la interacción de trofoblasto y endotelio en un modelo tridimensional de remodelación vascular y detección por ELISA del factor de crecimiento del endotelio vascular (VEGF). Se incluyeron 25 mujeres: con morbilidad gestacional y trombosis vascular (MG/TV, $n=7$ ) y con morbilidad gestacional únicamente (MG, $n=8)$, ambos grupos con presencia de aAFL; con morbilidad gestacional sin aAFL (MG/aFL-, $n=10$ ), y un grupo control de mujeres sanas ( $\mathrm{SHN}, \mathrm{n}=7$ ). Resultados: El suero de mujeres con morbilidad gestacional, MG/aAFL-, MG y MG/TV indujo disminución de la angiogénesis endotelial, pero en trofoblasto, únicamente el suero de los dos grupos de mujeres con aAFL tuvo este mismo efecto en concordancia con la reducción del VEGF. EI suero de mujeres con MG/aAFL- y MG/TV redujo elementos angiogénicos en el co-cutivo de trofoblasto y endotelio, comparado con el grupo control de SHN. En contraste con el grupo de MG/aAFL-, el suero de mujeres con aAFL, redujo la angiogénesis en células trofoblásticas y endoteliales. Conclusión: El efecto anti-angiogénico de los aAFL se observó focalizado en trofoblasto y el suero del grupo de mujeres con MG/ TV indujo mayores efectos deletéreos.

\section{PALABRAS CLAVE: Remodelación vascular, morbilidad gestacional, síndrome antifosfolípido, angiogénesis}

\section{SUMMARY}

Background: Antiphospholipid syndrome (APS) is characterized by manifestations of thrombosis or pregnancy morbidity and antiphospholipid antibodies (aAPL) which can bind to trophoblast or to maternal endothelium, altering normal placentation. Aims: To evaluate the effect of sera from patients with APS on a three-dimensional in vitro model of vascular remodeling. Methods: Systematic quantification of the interaction between trophoblast and endothelium with the software Image $\mathrm{J}$ and the plug-in Angiogenesis Analyzer in a three-dimensional model of vascular remodeling and the detection of vascular endothelial growth factor (VEGF) by ELISA. 25 women divided in three groups were included as follows: with pregnancy morbidity and thrombosis (PM/VT, $n=7$ ), pregnancy morbidity $(P M, n=8)$, both groups with aAPL; pregnancy morbidity 
without aAPL (PM/aAPL-, $n=10)$ and healthy women was used as control (NHS, $n=7)$. Results: Sera from women with gestational morbidity: PM/VT, PM, PM/aAPL-, decreased endothelial angiogenesis, but on trophoblast, only the sera of two groups of women with aAPL had this effect along with reduction of VEGF. Sera from women with PM/aAPL- and PM/VT reduced angiogenesis in the co-culture of trophoblast and endotelial cells compared to NHS. In contrast to PM/aAPL-, sera from women with APS decreased angiogenesis in trophoblastic cells. Conclusions: The anti-angiognic effect of aAPL was focused on trophoblast and sera from PM/VT induced higher deleterious effects.

\section{KEY WORDS: Vascular remodeling, pregnancy morbidity, antiphospholipid syndrome, angiogenesis}

\section{INTRODUCCIÓN}

La remodelación de las arterias espirales uterinas es un proceso fundamental para iniciar y preservar el flujo sanguíneo en la placenta durante la gestación (1). El citotrofoblasto endovascular que migra al lumen de las arterias espirales, copia el fenotipo de las células endoteliales (2). En la remodelación vascular normal se deben dar los procesos de angiogénesis y vasculogénesis, regulados por diferentes factores de crecimiento entre los cuales se encuentra el factor de crecimiento del endotelio vascular (VEGF) $(3,4)$. En un desarrollo placentario adecuado deben ocurrir los dos eventos, por lo que fallas o interrupciones de este proceso también pueden generar alteraciones en la gestación (5), entre las cuales podría considerarse la morbilidad gestacional asociada al síndrome antifosfolípido (SAF).

El SAF está definido como la presencia de anticuerpos antifosfolípidos (aAFL) persistentes, asociada a manifestaciones clínicas de trombosis vascular y/o morbilidad gestacional $(6,7)$. En células trofoblásticas los aAFL inducen apoptosis, inflamación y reducción de la invasión, y en células endoteliales, activan el endotelio llevando a una disfunción y a una inhibición de la angiogénesis (8-11).

Teniendo en cuenta estos efectos de los aAFL, el objetivo de este estudio es proponer un método sistematizado para cuantificar la remodelación vascular en un modelo tridimensional in vitro con el fin de desarrollar una herramienta para el estudio de la patogénesis de la morbilidad gestacional asociada al SAF.

\section{PACIENTES Y MÉTODO}

Población de estudio. Se incluyeron 25 mujeres que fueron clasificadas en los siguientes grupos: con morbilidad gestacional y trombosis vascular (MG/TV, $n=7)$ y con morbilidad gestacional únicamente (MG, $n=8$ ), ambos grupos cumpliendo con los criterios clínicos de Sapporo y con presencia de aAFL. Adicionalmente, se incluyó un tercer grupo de mujeres con morbilidad gestacional sin presencia de anticuerpos antifosfolípidos (MG/aFL, $n=10$ ), y un grupo control de mujeres sanas con embarazos previos sin complicaciones y sin aAFL (SHN, $n=7$ ). Todas las mujeres aceptaron participar en el estudio y firmaron un consentimiento informado aprobado por el Comité de Ética de la Sede de Investigación Universitaria de la Universidad de Antioquia.

Obtención de muestras. En los sueros de todas las mujeres del estudio se evaluó la presencia de: a) anticuerpos IgG anti-cardiolipina por un ELISA "home-made" y por un kit comercial (ACA ELISA kit, BioSystems, Barcelona, España) (12); b) anticuerpos IgG anti-ß2 glicoproteína I por el kit de ELISA Quanta Lite (Inova Diagnostics, California, USA); c) anticoagulante lúpico por tiempo parcial de tromboplastina activado usando el estuche comercial APTT-SP (Instrumentation laboratory Bedford, USA), y la determinación del tiempo de víbora de Russell con el estuche comercial LAC SCREEN para el tamizaje y el LAC CONFIRM para el confirmatorio (Rochem Biocare, Colombia). También se evaluó la positividad de otros aAFL "no-criterio" (anti-fosfatidilserina, antifosfatidil-inositol, anti-fosfatidilglicerol y anti-ácido fosfatídico), utilizando un ELISA "home-made". Para clasificar a las mujeres como positivas para cualquiera de los anticuerpos antifosfolípidos, debían ser positivas en dos ocasiones, con un intervalo mínimo de 12 semanas.

Cultivos celulares. Se utilizó la línea celular trofoblástica invasiva de primer trimestre HTR-8/ SVneo donada por el Dr. Charles Graham (Queens University, Kingston, Canada) (13). Las células fueron cultivadas en RPMI-1640 (Gibco, Grand Island, NY) suplementado con $10 \%$ de suero bovino fetal (SBF) (Gibco), $100 \mathrm{UI}$ de penicilina, $100 \mu \mathrm{g}$ de estreptomicina y $250 \mathrm{ng}$ de anfotericina B (Sigma, USA) a $37^{\circ} \mathrm{C} / 5 \%$ de $\mathrm{CO}_{2}$ y $60 \%$ de humedad relativa. Las células endoteliales de vena de cordón umbilical humano (HUVEC) fueron aisladas por digestión enzimática y mecánica de cordones umbilicales provenientes del parto de mujeres con un embarazo normal. Se perfundió la vena umbilical con una aguja pericraneal \#21, se adicionaron $5 \mathrm{ml}$ 
de colagenasa tipo I (Invitrogen, USA) ocluyendo los extremos con pinzas Kelly curvas y se incubó a $37^{\circ} \mathrm{C} / 20 \mathrm{~min}$. Se extrajo el contenido de la vena umbilical aplicando una fricción moderada y éste fue centrifugado a $300 \mathrm{xg} / 5 \mathrm{~min} / 22^{\circ} \mathrm{C}$. El botón de células resultante se cultivó en frascos con filtro de 175 cm2 Nunc ${ }^{T M}$ (Thermo Scientific, USA) con 10 $\mathrm{ml}$ de medio de cultivo basal de células endoteliales (MBCEs) suplementado con factores de crecimiento (factor de crecimiento de células endoteliales, factor de crecimiento epidermoide, factor de crecimiento básico de fibroblastos, heparina e hidrocortisona), a las concentraciones recomendadas por el fabricante (Promocell, Alemania) y $2 \%$ de SBF. Finalmente, después de 4 horas de cultivo se hicieron lavados con PBS y antibióticos para remover detritos y células no adherentes.

Cultivo tridimensional. Las células, HUVEC y HTR8, fueron cultivadas por separado o en cocultivo, en un sistema tridimensional in vitro. Las células HUVEC fueron marcadas con la sonda roja fluorescente PKH26 (Sigma) y las HTR8 con la sonda verde fluorescente PKH67 (Sigma) de acuerdo a las especificaciones del fabricante. En platos FalconTM (Thermo Fisher Scientific, USA) de 24 pozos se cultivaron $3 \times 10^{5}$ células HUVEC o HTR8 por pozo sobre $370 \mu$ l de Matrigel (BD-BiosciencesSan José) y $500 \mu$ de MBCEs o RPMI respectivamente. Después de 6 horas de cultivo se visualizó la formación de estructuras tubulares y se procedió a remover el sobrenadante. En los co-cultivos, las células HTR8 se adicionaron junto con los sueros después de las 6 horas para permitir la formación de estructuras tubulares de células HUVEC. En todos los casos las células fueron cultivadas por 12 horas con $500 \mu \mathrm{l}$ de Opti-MEM (Gibco) y 10\% de pool de suero de cada uno de los grupos de las mujeres del estudio. Como control del ensayo las células HUVEC y HTR8 se cultivaron con SBF.

Análisis de imágenes. De cada pozo se adquirieron fotografías de 4 campos con un objetivo de 5X (EC Epiplan-Neofluar, Zeiss) con la cámara DSfi1 (Nikon, Japón) adaptada a un microscopio de fluorescencia Axio Vert.A1 (Zeiss, Alemania). Cada fotografía fue procesada y analizada con el programa Image J versión 1.51a (http: //rsb.info.nih.gov./ ij/) de descarga libre y el complemento Angiogenesis Analyzer desarrollado por Gilles Carpentier el cual procesa las imágenes de la organización pseudo-vascular detectando elementos angiogénicos, de los cuales se incluyeron doce: 1) número de redes, 2) área ocupada por redes, 3) número de uniones 4) número de uniones principales, 5) número de ramificaciones, 6) longitud de ramificaciones 7) número de extremidades 8) número de segmentos, 9) longitud de segmentos, 10) número de segmentos principales, 11) longitud de segmentos principales y 12) área cubierta por las células HTR8 y por las células HUVEC obtenido por un análisis de imágenes binarias con el programa Image J.

Detección de VEGF. En los sobrenadantes obtenidos en los cultivos descritos, se detectó la producción de VEGF por un kit de ELISA de acuerdo a las especificaciones del fabricante Novex ${ }^{\mathrm{TM}}$ (Invitrogen, USA). El kit detecta la isoforma de 165 aminoácidos por un ELISA tipo sándwich con un límite de detección de $5 \mathrm{pg} / \mathrm{ml}$.

Análisis estadístico. Los ensayos fueron realizados por triplicado. Los datos se muestran como el promedio y el error estándar de la media (SEM). Sobre los datos obtenidos se aplicó la prueba de normalidad Kolmogorov-Smirnov. La significancia estadística $(p<0,05)$ fue determinada con un ANOVA de una vía y un post-test de Dunnett.

\section{RESULTADOS}

El grupo de mujeres con MG/TV presentó positividad para todas las pruebas de laboratorio incluidas en los criterios de Sapporo (7). En el grupo de mujeres con MG se detectaron anticuerpos anticardiolipina persistentes por el ELISA "home-made" pero no por los kit comerciales. A pesar de esto, se decidió incluir a estas pacientes en el estudio ya que también presentaban positividad para otros anticuerpos no-criterio dirigidos a fosfolípidos cargados negativamente evaluados también por el ELISA "home-made" cuya inclusión como criterios de clasificación, aún se encuentra en discusión (14). El grupo de mujeres con MG/aAFL- y el grupo control de mujeres sanas SHN, fueron negativas para todas las pruebas de laboratorio de aAFL (Tabla I).

En contraste con el grupo control de SHN, el número de redes fue reducido en células HUVEC por el suero de los tres grupos de mujeres con morbilidad gestacional (MG/aAFL-, MG y MG/TV) y el área ocupada por redes fue disminuida solo por el suero de las mujeres con aAFL (MG y MG/TV). En células HTR8 se observó el mismo efecto inducido por el suero de mujeres con MG/TV; en el co-cultivo tanto el suero del grupo MG/aAFL-, como del MG/ TV provocó esta reducción (Figura 1 A y B). Como análisis adicionales y con el fin de esclarecer más específicamente el efecto de los aAFL sobre estos elementos angiogénicos, se comparó el resultado del suero de mujeres con MG/aAFL-, con el de los dos grupos de pacientes con aAFL (MG y MG/TV) y se encontró que estos sueros redujeron el número de redes y el área ocupada por redes en células HTR8 únicamente (Figura $1 \mathrm{~A}$ y $B$ ). 


\section{Tabla I}

CARACTERÍSTICAS DE LAS MUJERES INCLUIDAS EN EL ESTUDIO

\begin{tabular}{|c|c|c|c|c|}
\hline Parámetro & $\begin{array}{l}\text { SHN } \\
(n=7)\end{array}$ & $\begin{array}{l}\text { MG/aAFL- } \\
\quad(n=10)\end{array}$ & $\begin{array}{l}M G \\
(n=8)\end{array}$ & $\begin{array}{c}\mathrm{MG} / \mathrm{TV} \\
(\mathrm{n}=7)\end{array}$ \\
\hline Edad (media de años \pm SEM) & $36,1 \pm 2,44$ & $30,8 \pm 1,82$ & $33 \pm 1,8$ & $37,1 \pm 2,2$ \\
\hline \multicolumn{5}{|l|}{ Pérdidas fetales (media y rango) } \\
\hline $\begin{array}{l}\leq 10 \text { semanas de gestación } \\
>10 \text { semanas de gestación }\end{array}$ & $\begin{array}{l}0 \\
0\end{array}$ & $\begin{array}{l}2,1(1-5) \\
0,4(0-3)\end{array}$ & $\begin{array}{c}1(1-4) \\
0,75(1-2)\end{array}$ & $\begin{array}{l}2(2-5) \\
1,4(1-5)\end{array}$ \\
\hline $\begin{array}{l}\text { Preeclampsia }<34 \text { semanas } \\
\text { (número de pacientes) }\end{array}$ & 0 & 0 & 0 & 4 \\
\hline $\begin{array}{l}\text { Trombosis arterial/venosa } \\
\text { (número de pacientes) }\end{array}$ & 0 & 0 & 0 & 7 \\
\hline AL positivo & 0 & 0 & 1 & 7 \\
\hline Anti- $\beta 2$ glicoproteína I SGU & 3,69 & 4,36 & 4,71 & 85,76 \\
\hline $\begin{array}{l}\text { Anti cardiolipina por el ELISA Aca } \\
\text { (media GPLU +/-) }\end{array}$ & 10,09 & 6,79 & 8,95 & 93,24 \\
\hline $\begin{array}{l}\text { Anti cardiolipina por ELISA home-made } \\
\text { (media de densidad óptica de pacientes } \\
\text { / media de densidad óptica del control } \\
\text { positivo, \% de control }\end{array}$ & 9,73 & 0 & 21,93 & 87,47 \\
\hline $\begin{array}{l}\text { Otros anticuerpos en suero } \\
\text { (\% de positividad de pacientes con } \\
\text { respecto al control positivo) }\end{array}$ & $\begin{array}{l}\text { GPI: } 0 \\
\text { GPG: } 15,03 \\
\text { GPS: } 6,57 \\
\text { GPA: } 4,23\end{array}$ & $\begin{array}{l}\text { GPI: } 0 \\
\text { GPG: } 0 \\
\text { GPS: } 0 \\
\text { GPA: } 0\end{array}$ & $\begin{array}{l}\text { GPI: } 39,17 \\
\text { GPG: } 32,13 \\
\text { GPS: } 45,63 \\
\text { GPA: } 15,03\end{array}$ & $\begin{array}{l}\text { GPI: } 58,77 \\
\text { GPG: } 74,37 \\
\text { GPS: } 80,7 \\
\text { GPA: } 97,03\end{array}$ \\
\hline
\end{tabular}

SHN: Mujeres sanas. MG/aFL-: mujeres con morbilidad gestacional sin presencia de anticuerpos antifosfolípidos. MG: mujeres con morbilidad gestacional únicamente. MG/TV: mujeres con morbilidad gestacional y trombosis vascular. AL: anticoagulante lúpico. SGU: unidades estándar de inmunoglobulina G Anti-ß2 glicoproteína I. GPLU: unidades estándar de inmunoglobulina $\mathrm{G}$ anti-cardiolipina. GPI: inmunoglobulina $\mathrm{G}$ anti-fosfatidilinositol. GPG: inmunoglobulina $\mathrm{G}$ antifosfatidilglicerol. GPS: inmunoglobulina G anti-fosfatidilserina. GPA: inmunoglobulina G anti-ácido fosfatídico.

En células HUVEC, el número de uniones y uniones principales, ramificaciones, longitud de ramificaciones, y número de extremidades fue reducido por el suero de los tres grupos de mujeres con morbilidad gestacional comparado con el control de SHN (Figura 2 A y B). En células HTR8, sólo el suero del grupo de mujeres con MG/TV disminuyó el número de uniones y uniones principales. Los otros tres elementos angiogénicos se redujeron en presencia del suero de mujeres con MG y MG/TV. En comparación con MG/aAFL-, solo en células HTR8 el suero de los dos grupos con aAFL, redujo el número de estos cinco elementos angiogénicos con excepción del número de extremidades que no se observó significativamente disminuido por MG/TV (Figura 2 A y B). En el co-cultivo no se observaron diferencias (datos no mostrados).

El número de segmentos en células HUVEC se redujo en presencia del suero del grupo de mujeres con aAFL, comparado con el control de SHN y el suero de mujeres con MG/aAFL-. El número, y la longitud de segmentos y segmentos principales se observaron disminuidos en los cultivos con el suero de los tres grupos de mujeres con morbilidad gestacional. En células HTR8, el suero de mujeres con aAFL, redujo los cuatro elementos mencionados anteriormente en contraste con SHN o MG/aAFL(Figura $3 \mathrm{~A}$ y B). En el co-cultivo no se observaron diferencias significativas (datos no mostrados).

En los análisis de imágenes binarias se encontró que comparado con el SHN, tanto el suero de mujeres del grupo MG/aAFL- como el de MG/TV, indujo reducción en el porcentaje de área cubierta por células HUVEC al igual que el suero de las mujeres con aAFL en las células HTR8 (Figura 4 $A$ y B). En contraste con el suero de mujeres con MG/aAFL-, el del grupo con MG/TV disminuyó el porcentaje de área cubierta por HTR8. En el co-cultivo, se observó que el suero de los dos grupos de mujeres con aAFL indujo esta reducción en células HTR8 pero no en células HUVEC (Figura 4 A y B). 

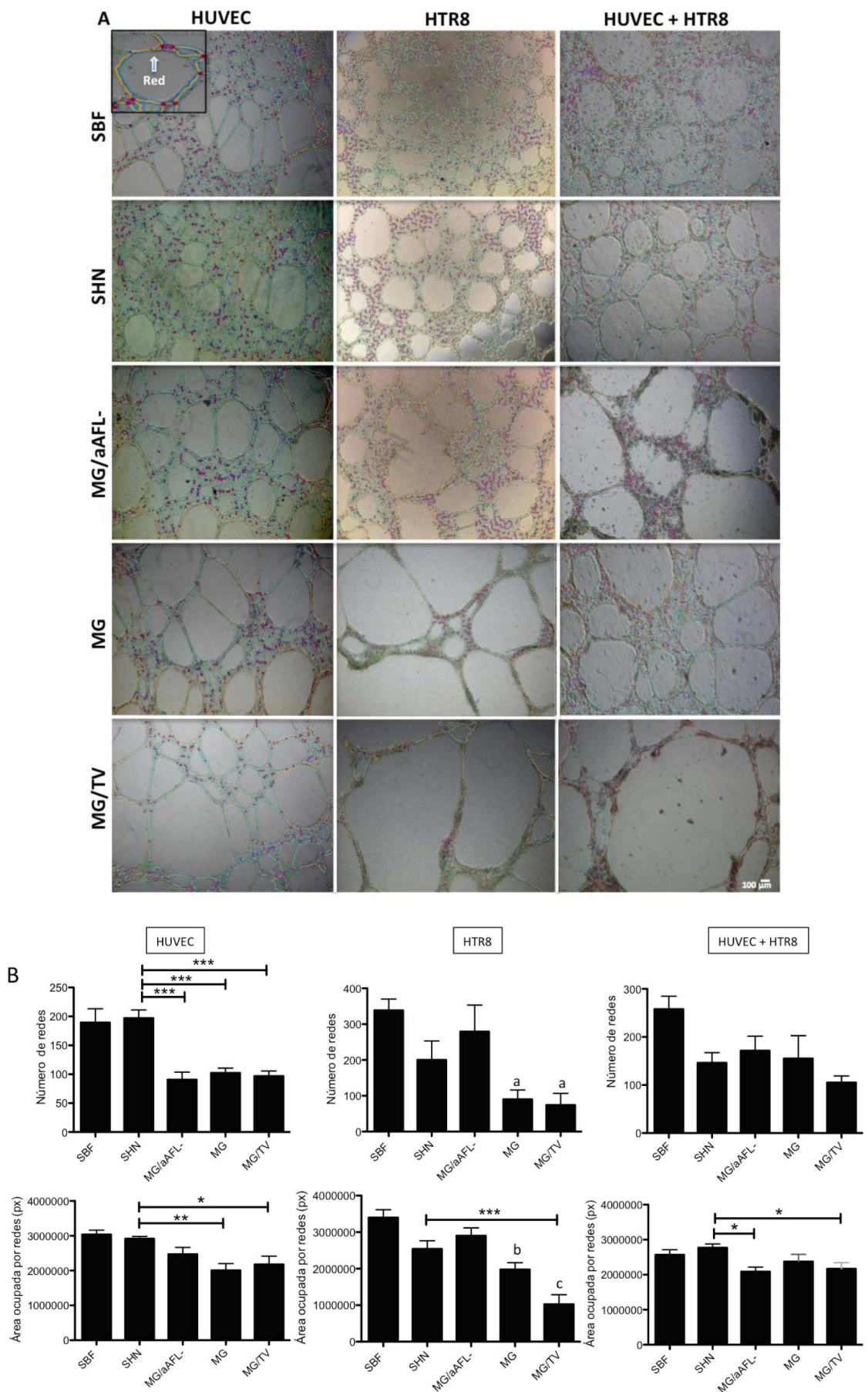

Figura 1. Efecto del suero de los grupos de las mujeres del estudio en el número de redes y el área ocupada por redes en células HUVEC, HTR8 o en co-cultivo. Como se indica con la flecha las redes corresponden a las estructuras delimitadas con la línea azul. Los datos se obtuvieron con el complemento Angiogenesis Analyzer en el programa Image J. Valores de $p$ en comparación con el grupo control de $\mathrm{SHN}$ : ${ }^{*} \mathrm{p}<0,05$, ${ }^{* *} p<0,01,{ }^{* * *} p<0,001$. Las letras a, b y c indican: $p<0,05, p<0,01, p<0,001$ respectivamente en contraste con el suero de MG/aAFL-. 

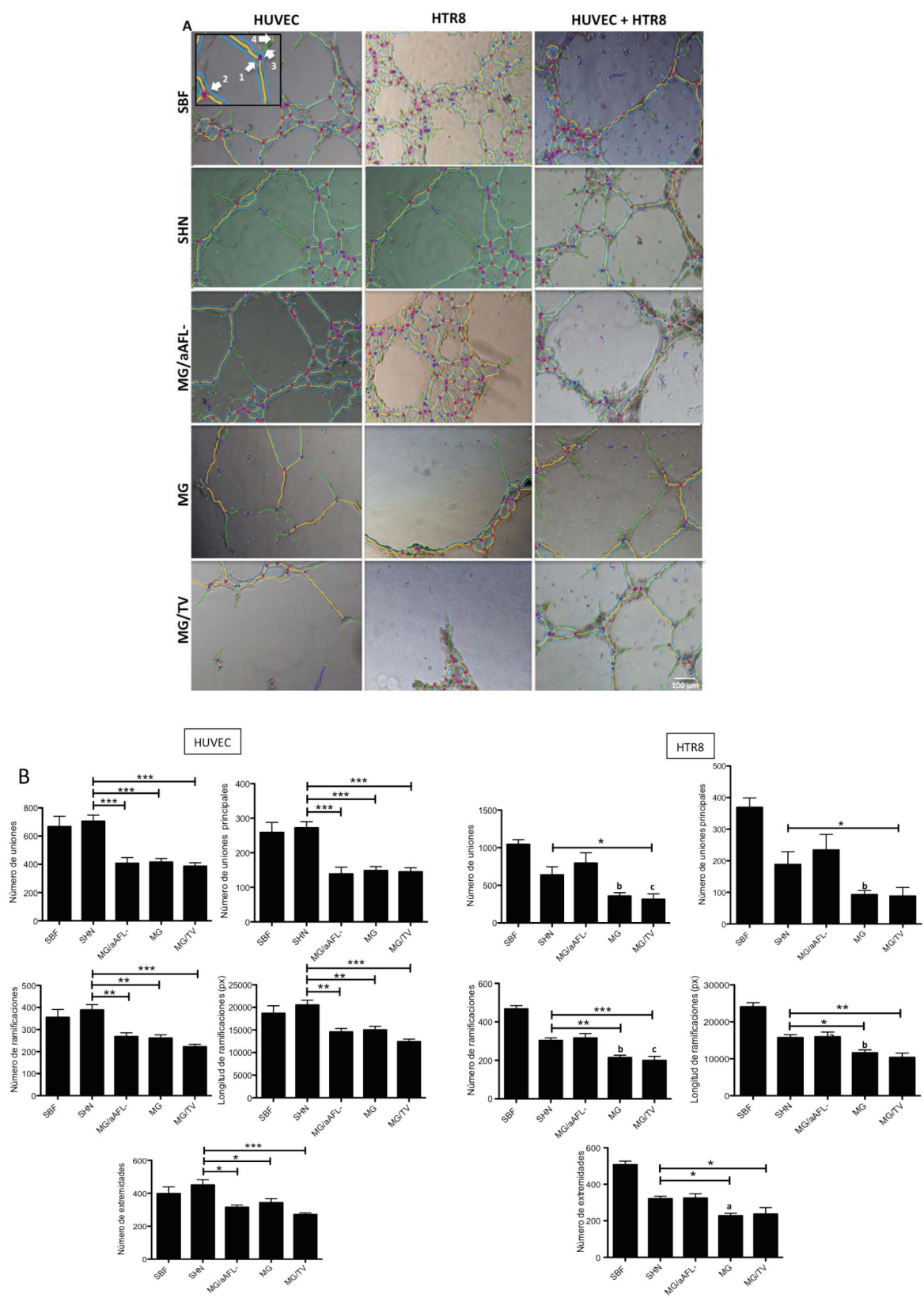

Figura 2. Efecto del suero de los grupos de las mujeres del estudio sobre el número de uniones, uniones principales, ramificaciones, longitud de ramificaciones y número de extremidades en células HUVEC, HTR8 o en co-cultivo. Con las flechas se indican los elementos angiogénicos: 1) unión, corresponde al círculo rojo rodeado de otro azul, uniendo dos segmentos (estructuras en amarillo) y una ramificación (estructuras en verde); 2) unión principal, se indica como una unión rodeada de un círculo rojo adicional en la cual se unen tres segmentos; 3) Ramificación, corresponde a las estructuras finales, delimitadas con la línea verde; 4) Extremidad, se observa al final de las ramificaciones como un círculo amarillo rodeado de otro naranjado. Valores de $p$ en comparación con el grupo control de $S H N$ : ${ }^{*} p<0,05,{ }^{* *} p<0,01,{ }^{* * *} p<0,001$. Las letras a, b y $c$ indican: $p<0,05, p<0,01, p<0,001$ respectivamente en contraste con el suero de MG/aAFL-. Se muestran únicamente las fotografías representativas de los co-cultivos pero no las gráficas, ya que no se encontraron diferencias significativas entre grupos. 

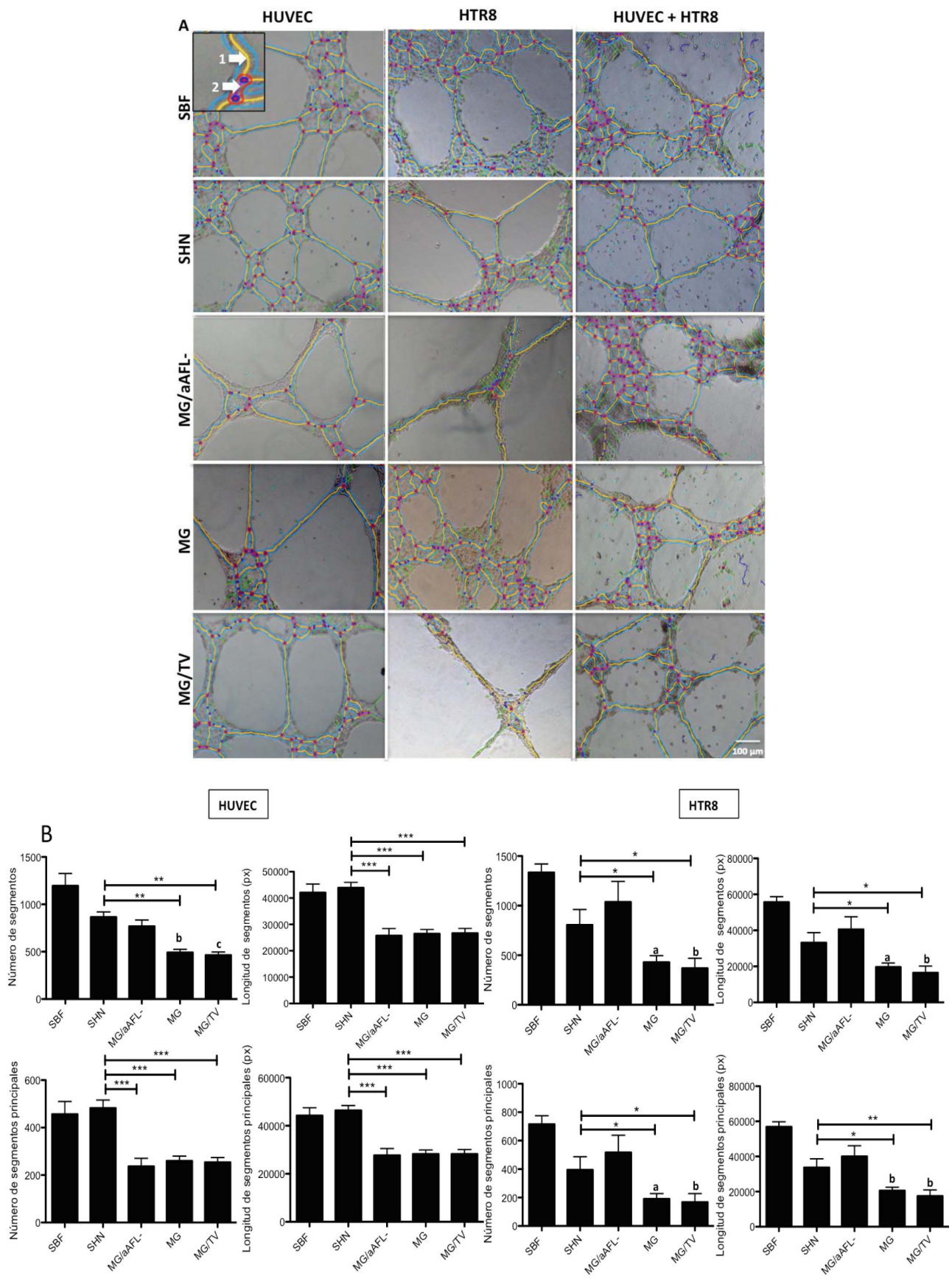

Figura 3. Efecto del suero de los grupos de las mujeres del estudio sobre el número y longitud de segmentos y segmentos principales en células HUVEC, HTR8 o en co-cultivo. Con las flechas se indican los elementos angiogénicos: 1) segmentos, estructuras identificadas con la línea amarilla que forman las redes; 2) segmentos principales, corresponden a la unión de dos uniones principales y se indican con la línea en color magenta. Valores de $p$ en comparación con el grupo control de SHN: ${ }^{*} p<0,05,{ }^{* *} p<0,01,{ }^{* * *} p<0,001$. Las letras a, b y $c$ indican: $p<0,05, p<0,01, p<0,001$ respectivamente en contraste con el suero de MG/ aAFL-. En los co-cultivos se muestran únicamente las fotografías representativas pero no las gráficas, ya que no se encontraron diferencias significativas entre grupos. 

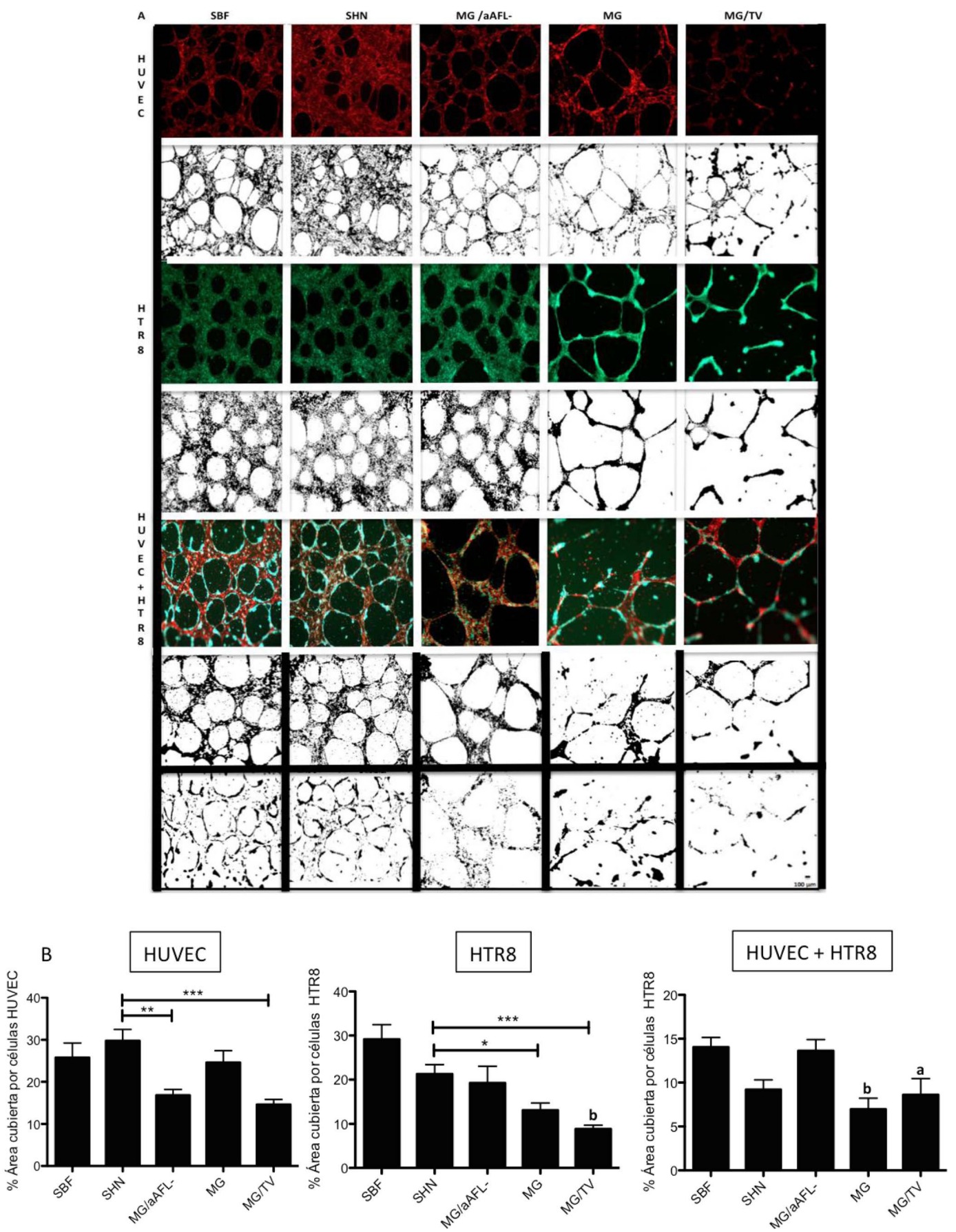

Figura 4. Efecto del suero de los grupos de las mujeres del estudio sobre el porcentaje de área cubierta por células HUVEC, HTR8 solas o en co-cultivo. Para todos los casos las imágenes en rojo corresponden a las estructuras formadas por células HUVEC y las verdes por células HTR8. Valores de p en comparación con el grupo control de SHN: ${ }^{*} p<0,05,{ }^{* *} p<0,01,{ }^{* *} p<0,001$. Las letras a y b indican: $p<0,05$ y $p<0,01$ respectivamente en contraste con el suero de MG/aAFL-. Se muestran únicamente las fotografías representativas de las células HUVEC en los co-cultivos pero no la gráfica, ya que no se encontraron diferencias significativas entre grupos. 
En los sobrenadantes de las células HTR8 se encontró una disminución significativa de VEGF en los cultivos estimulados con los sueros de los grupos de pacientes MG y MG/TV, en contraste con el grupo control de SHN (Figura 5). En células HUVEC solas, o en co-cultivo con células HTR8 no se observaron diferencias (Figura 5).

\section{DISCUSIÓN}

En los reportes de la literatura, desde el 2007 que inició el desarrollo del modelo tridimensional de interacción de células trofoblásticas y endoteliales, se analizan las imágenes obtenidas mediante el conteo manual de las estructuras tubulares, las redes o el área cubierta por células (2,15-17). A este modelo se le han conferido propiedades predictivas ya que el suero de las mujeres gestantes en el primer trimestre del embarazo que posteriormente desarrollaron preeclampsia, provocaron una disrupción en las estructuras tubulares (18). En el presente estudio, se optimizó el modelo de remodelación vascular a través de la cuantificación de cada una de las imágenes obtenidas de manera sistematizada y detallada, con el programa gratuito Image $\mathrm{J}$ y el complemento Angiogenesis analyzer, lo cual facilitó la obtención de los datos, minimizando el error que podrían tener los conteos manuales.

En general, el suero del grupo de mujeres con MG/TV tuvo mayores efectos deletéreos que el de MG en comparación con el grupo control de SHN, ya que disminuyó el 100\% de los elementos angiogénicos en células HUVEC, el 91,6\% en HTR8 y el $8,3 \%$ en el co-cultivo, lo que podría explicarse por los mayores niveles de aAFL y la presencia de trombosis en este grupo. Resultados similares fueron encontrados en trabajos previos realizados por algunos investigadores de nuestro grupo, donde se evaluó el efecto del suero de estos mismos grupos de mujeres excepto el de MG/aAFL- en el modelo de interacción de una línea de células endoteliales endometriales (HEEC) y células HTR8 después de 48 horas de cultivo, encontrándose un efecto deletéreo en presencia del suero de mujeres con MG y MG/TV, evidenciado por el conteo manual del número de redes en cada imagen adquirida (19).

En presencia del suero de los dos grupos de mujeres con aAFL (MG y MG/TV) y en comparación con el de mujeres negativas para aAFL (MG/ aAFL-) el cual no afectó la angiogénesis de células trofoblásticas, se observó una reducción de la angiogénesis de un $91,6 \%$ (11 de 12 elementos evaluados) focalizado en las células trofoblásticas, lo que podría explicarse a través de la reducción de VEGF que fue observada en estas células y no en las endoteliales. Se ha reportado que en trofoblasto primario de primer trimestre, un anticuerpo monoclonal anti-ß2GPI, incrementó la producción de sFlt-1 (tirosina quinasa 1 similar al fms o receptor del factor estimulante de colonias de macrófagos 1 , receptor soluble del VEGF) el cual es un potente inhibidor de la angiogénesis (20). Estos mismos autores encontraron que la IgG purificada a partir del suero de mujeres con SAF aumenta la producción de este factor sFlt-1 en células HTR8 en contraste con células no tratadas (20).

En células HUVEC, el suero de MG/aAFL- indujo reducción de la angiogénesis en un 83,3\% (10 de 12 elementos) si bien estas pacientes son negativas para los aAFL y aún deben ser estudiados los mecanismos que alteraron la angiogénesis y la remodelación vascular, se ha reportado que eventos proinflamatorios contribuyen al desarrollo de la morbilidad gestacional y que a su vez la inflamación inhibe la remodelación vascular $(21,22)$. En cuanto a los efectos encontrados en el co-cultivo, el
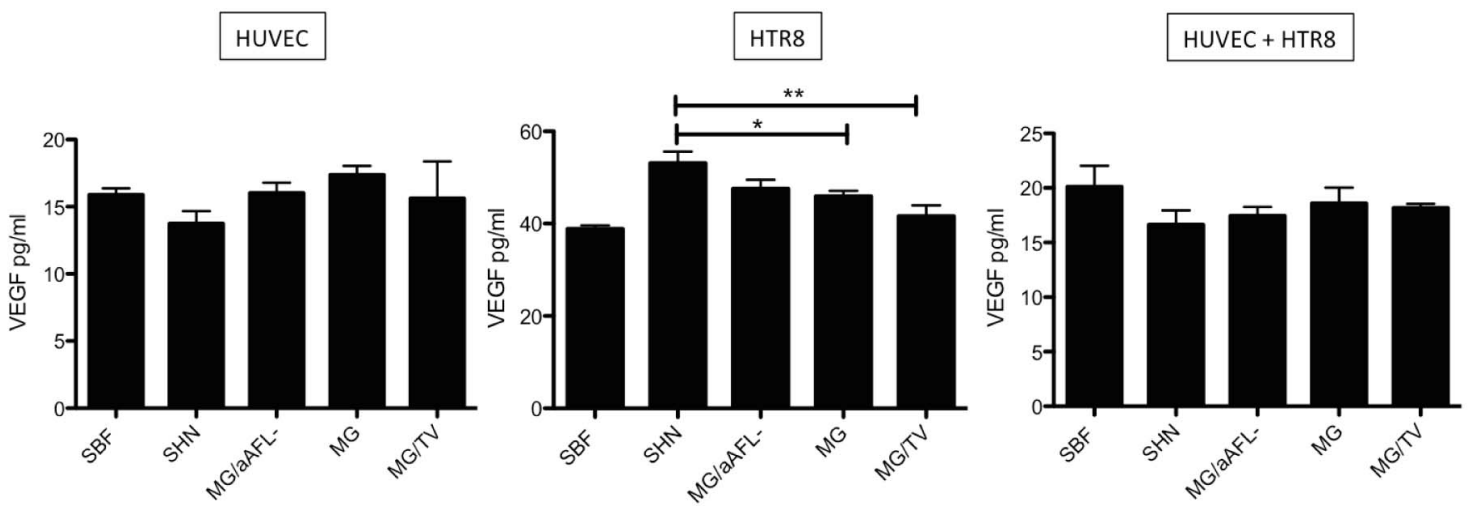

Figura 5. Efecto del suero de los grupos de las mujeres del estudio sobre el la producción de VEGF en los cultivos de células HUVEC y HTR8 en co-cultivo o solas. Valores de p en comparación con el grupo control de SHN: ${ }^{*} p<0,05,{ }^{* *} p<0,01$. 
suero de los tres grupos de mujeres con morbilidad gestacional, con o sin aAFL, redujo sólo uno de los elementos evaluados, lo que sugiere que existen otros componentes deletéreos en la remodelación vascular, sin embargo es claro que los aAFL estarían potenciando los efectos anti-angiogénicos, en el contexto de la morbilidad gestacional, como ha sido reportado en otros modelos de estudio con aAFL en trofoblasto y endotelio respectivamente $(10,20)$

\section{CONCLUSIONES}

Los títulos más altos de aAFL y la presencia de otras manifestaciones clínicas del SAF como la trombosis, potencian los efectos anti-angiogénicos alterando por ende la remodelación vascular. Los aAFL afectan de manera focalizada la capacidad angiogénica de las células trofoblásticas evidenciado en el modelo tridimensional in vitro y en la disminución en la producción de VEGF.

Agradecimientos: Este proyecto fue financiado por el CODI-Universidad de Antioquia, código 9-1-515 y la Estrategia Sostenibilidad. MVB fue joven investigadora de Colciencias.

\section{REFERENCIAS}

1. Tsatsaris V, Malassiné A, Fournier T, Handschuh K, Schaaps J-P, Foidart J-M, et al. Placenta humana EMC-Ginecología-Obstetricia. 2006;42(2):1-23.

2. Kalkunte S, Lai Z, Tewari N, Chichester C, Romero R, Padbury J, et al. In vitro and in vivo evidence for lack of endovascular remodeling by third trimester trophoblasts. Placenta. 2008;29(10):871-8.

3. Bischof $\mathrm{P}$, Irminger-Finger I. The human cytotrophoblastic cell, a mononuclear chameleon. Int J Biochem Cell Biol. 2005;37(1):1-16.

4. Zygmunt M, Herr F, Munstedt K, Lang U, Liang OD. Angiogenesis and vasculogenesis in pregnancy. Eur J Obstet Gynecol Reprod Biol. 2003;110 Suppl 1:S108.

5. Bdolah Y, Sukhatme VP, Karumanchi SA. Angiogenic imbalance in the pathophysiology of preeclampsia: newer insights. Semin Nephrol. 2004;24(6):548-56.

6. Lockshin MD. Antiphospholipid antibody syndrome. Rheum Dis Clin North Am. 1994;20(1):45-59.

7. Miyakis S, Lockshin MD, Atsumi T, Branch DW, Brey $\mathrm{RL}$, Cervera $\mathrm{R}$, et al. International consensus statement on an update of the classification criteria for definite antiphospholipid syndrome (APS). J Thromb Haemost. 2006;4(2):295-306.

8. Mulla MJ, Brosens JJ, Chamley LW, Giles I, Pericleous C, Rahman A, et al. Antiphospholipid antibodies induce a pro-inflammatory response in first trimester trophoblast via the TLR4/MyD88 pathway. Am J Reprod Immunol. 2009;62(2):96-111.
9. Martinez-Sales V, Vila V, Mico L, Contreras MT, Escandell A, Reganon E. [Circulating endothelial cells and microparticles in patients with antiphospholipid antibodies]. Medicina clinica. 2011;136(10):431-3.

10. Di Simone N, Di Nicuolo F, D'Ippolito S, Castellani R, Tersigni C, Caruso A, et al. Antiphospholipid antibodies affect human endometrial angiogenesis. Biol Reprod. 2010;83(2):212-9.

11. Kovacevic TM, Radojcic L, Tosic NM, Pavlovic ST, Vicovac LM. Monoclonal antibody 26 cross-reactive with beta2-glycoprotein I affects human trophoblast invasion in vitro. Eur J Obstet Gynecol Reprod Biol. 2013;171(1):23-9.

12. Pena RB, Cadavid AP, Botero JH, Garcia GP, Gallego MI, Ossa JE. The production of MLR-blocking factors after lymphocyte immunotherapy for RSA does not predict the outcome of pregnancy. Am J Reprod Immunol. 1998;39(2):120-4.

13. Graham CH, Hawley TS, Hawley RG, MacDougall JR, Kerbel RS, Khoo N, et al. Establishment and characterization of first trimester human trophoblast cells with extended lifespan. Exp Cell Res. 1993;206(2):204-11.

14. Bertolaccini ML, Amengual O, Atsumi T, Binder WL, de Laat B, Forastiero R, et al. 'Non-criteria' aPL tests: report of a task force and preconference workshop at the 13th International Congress on Antiphospholipid Antibodies, Galveston, TX, USA, April 2010. Lupus. 2011;20(2):191-205.

15. Xu B, Charlton F, Makris A, Hennessy A. Nitric oxide (NO) reversed TNF-alpha inhibition of trophoblast interaction with endothelial cellular networks. Placenta. 2014;35(6):417-21.

16. Xu B, Charlton F, Makris A, Hennessy A. Antihypertensive drugs methyldopa, labetalol, hydralazine, and clonidine improve trophoblast interaction with endothelial cellular networks in vitro. J Hypertension. 2014;32(5):1075-83; discussion 83.

17. Aldo PB, Krikun G, Visintin I, Lockwood C, Romero R, Mor G. A novel three-dimensional in vitro system to study trophoblast-endothelium cell interactions. Am J Reprod Immunol. 2007;58(2):98-110.

18. Kalkunte S, Boij R, Norris W, Friedman J, Lai Z, Kurtis $\mathrm{J}$, et al. Sera from preeclampsia patients elicit symptoms of human disease in mice and provide a basis for an in vitro predictive assay. Am J Pathol. 2010;177(5):2387-98.

19. Alvarez AM, Mulla MJ, Chamley LW, Cadavid AP, Abrahams VM. Aspirin-triggered lipoxin prevents antiphospholipid antibody effects on human trophoblast migration and endothelial cell interactions. Arthritis Rheumatol. 2015;67(2):488-97.

20. Carroll TY, Mulla MJ, Han CS, Brosens JJ, Chamley LW, Giles I, et al. Modulation of trophoblast angiogenic factor secretion by antiphospholipid antibodies is not reversed by heparin. Am J Reprod Immunol. 2011;66(4):286-96.

21. Osborne LM, Monk C. Perinatal depression--the fourth inflammatory morbidity of pregnancy?: Theory and literature review. Psychoneuroendocrinology. 2013;38(10):1929-52.

22. Cotechini T, Komisarenko M, Sperou A, MacdonaldGoodfellow S, Adams MA, Graham CH. Inflammation in rat pregnancy inhibits spiral artery remodeling leading to fetal growth restriction and features of preeclampsia. J Exp Med. 2014;211(1):165-79. 